\title{
ESTRUCTURAS FUNDAMENTALES CONCRETAS
}

\author{
José TOMÁs AlVARADO MARAMBIO \\ https://orcid.org/0000-0003-2324-8458 \\ Pontificia Universidad Católica de Chile \\ Instituto de Filosofía \\ Av. Vicuña Mackenna 4860, Macul-Santiago, C. P. 7820436, Chile \\ jalvaram@uc.cl / jose.tomas.alvarado@gmail.com
}

\author{
Article info \\ CDD: 530.01 \\ Received: 04.07.2018; Revised: 24.10.2018; Accepted: 07.11.2018 \\ DOI: http://dx.doi.org/10.1590/0100-6045.2019.V42N1.JA
}

Keywords / Palabras claves:

Ontic Structural Realism

Realismo estructural óntico

Structures

Estructuras

Relations

Relaciones

Trope Bundles

Cúmulos de tropos

Substrata

Sustratos

\begin{abstract}
Several problems in philosophy of physics have led to 'ontic structural realism', i. e., the supposition that, at the fundamental physical level, there are no 'objects', but 'structures'. There are various requirements that a 'structure' should satisfy for 'ontic structural realism'. Structures must be concrete entities, there must be something that fulfills the role of 'node', and the relations of the structure must not be dependent on the objects that are being related. Most of the traditional ontologies, both of substrata and properties, and of bundles of properties, seem to be inadequate to satisfy those requirements. It is argued here that there are several ways in which those requirements can be met: by nodal relations, by primitive 'nodal facts', and by symmetric dependencies between objects and relations.
\end{abstract}

Resumen: Varios problemas en la filosofía de la física han llevado al 'realismo estructural óntico', esto es, la suposición de 
que en el nivel físico fundamental no hay 'objetos', sino 'estructuras'. Hay varios requerimientos que una 'estructura' debe satisfacer para el 'realismo estructural óntico'. Las estructuras deben ser entidades concretas, debe haber algo que cumpla las funciones de 'nodo', y las relaciones no deben depender de los objetos que están siendo relacionados. La mayoría de las ontologías tradicionales, tanto de sustratos y propiedades, como de ámulos de propiedades, parecen ser inadecuadas para satisfacer tales requerimientos. Se argumenta aquí que hay varias formas en que tales requerimientos podrían ser solventados: por relaciones nodales, por 'hechos nodales' primitivos y por dependencias simétricas entre objetos y relaciones.

En años recientes se han propuesto ontologías 'estructuralistas' en una serie de áreas de filosofía de la física (cf. para presentaciones generales, Ladyman, Ross et al., 2007, 130-189; French y Ladyman, 2011; French, 2014, 101-230; Ladyman, 2014; Lam, 2017). En estas ontologías se pretende reducir o eliminar a los objetos por 'estructuras' de carácter relacional. Hay diferentes motivaciones para estas ontologías. Por un lado, se han presentado como una radicalización del 'realismo estructural epistémico' (cf. Worrall, 1989) pero, por otro lado, han pretendido resolver cuestiones específicas que tienen que ver, por ejemplo, con la individuación de partículas en mecánica cuántica, con el entrelazamiento (entanglement) cuántico y con el estatuto ontológico del espacio-tiempo en la teoría de la relatividad general, entre otras. En este trabajo no se va a discutir la pertinencia de estas motivaciones para el llamado "realismo estructural óntico". La cuestión general que será considerada es la coherencia del concepto de una 'estructura física'. En efecto, varios filósofos han sostenido que la mera idea de una 'estructura', esto es, la mera idea de un plexo de relaciones, requiere la existencia de objetos que estén siendo relacionados (cf. Cao, 2003; Chakravartty, 2003; Morganti, 2004; Psillos, 2006, Briceño y Mumford, 
2016; una posición más moderada, Esfeld, 2004; Esfeld y Lam, 2011; McKenzie, 2014). Resultaría, entonces, que la pretensión de reducir o eliminar a los objetos de nuestra ontología por estructuras -por lo menos, en lo que concierne a la física- sólo se puede ejecutar al precio de postular objetos. Entonces, no es posible reducir o eliminar objetos por estructuras y el estructuralismo óntico adolecería de un problema de coherencia básico.

Se va a argumentar aquí que hay varias formas de concebir coherentemente una estructura física concreta, no fundada en objetos, ni dependiente de objetos, y que puede ser el fundamento de lo que entendemos ordinariamente por un 'objeto' o, eventualmente, puede permitir la eliminación de los objetos. Una estructura debe ser entendida como una especie de cúmulo de tropos, pero con diferencias importantes respecto de las formas usuales en que los cúmulos de tropos han sido concebidos. Se requiere, en especial, comprender los 'nodos' de una estructura $^{1}$ o bien como hechos primitivos, o bien como tropos relacionales. Una ontología de estructuras exige, por lo tanto, reformas importantes en los esquemas ontológicos tradicionales. No es extraño, por esto, que la idea de 'estructuras físicas' haya sido recibida con escepticismo. Se mostrará aquí, sin embargo, que no hay ningún problema de coherencia con la hipótesis de estructuras físicas fundamentales.

En lo que sigue de este trabajo, se va a explicar qué requerimientos tendría una estructura física fundamental (\$ 1). Una estructura física debe ser una entidad concreta y debe incluir relaciones y algo que cumpla las funciones de un 'nodo' para conformarla. En segundo lugar, se va a explicar por qué las ontologías tradicionales de sustratos o de cúmulos se han mostrado inadecuadas para conformar

1 'Nodos' en el sentido en que se entiende esta expresión en teoría de grafos, tal como se va a explicar más abajo. 
estas estructuras físicas fundamentales ( $(2)$. En la tercera y última parte se explicará de qué modo pueden ser entendidas estas estructuras físicas como una forma especial de cúmulo de tropos relacionales ( $(\mathbb{3})$.

\section{$\int$ 1. REQUERIMIENTOS DE UNA ESTRUCTURA FÍSICA FUNDAMENTAL}

¿Qué sería una 'estructura física fundamental'? La expresión "estructura" no dice demasiado por sí misma. Se la ha utilizado en contextos muy diferentes para significar también cosas muy distintas ${ }^{2}$. De un modo muy general, una 'estructura' puede ser caracterizada como una colección de entidades relacionadas o dispuestas entre sí. En algunos casos, la 'estructura' designará más bien la disposición resultante de tales relaciones tomada con independencia de qué sean aquellas entidades relacionadas. En otros casos, la 'estructura' designará más bien el todo estructurado de esas entidades con tal disposición. Es útil en este punto considerar cómo es que en matemáticas se ha definido un 'grafo' (cf. Balakrishnan y Ranganathan, 2012). La teoría de grafos, en efecto, es una teoría que estudia de un modo abstracto colecciones de objetos relacionados entre sí. Un grafo se define formalmente por un conjunto de 'nodos',

${ }^{2}$ No escapará a la atención el hecho de que en la misma filosofía general de la ciencia se ha denominado como "concepción estructuralista de las teorías" algo que tiene poco que ver con el realismo estructural óntico. La concepción 'estructuralista' sostiene que las teorías científicas deben entenderse como conjuntos de modelos que satisfacen una cierta 'estructura' axiomática. El realismo estructural óntico no tiene ver con la naturaleza de nuestras teorías por las que pretendemos describir la realidad física, sino con la naturaleza de esa realidad física en su nivel fundamental. Algo semejante debería decirse del llamado ‘enfoque semántico' de las teorías. 
'vértices' o 'puntos', y un conjunto de 'lados' o 'íneas' que conectan tales nodos ${ }^{3}$. No interesa qué es lo que sea un nodo y qué es lo que sea un $\mathrm{lado}^{4}$, pero interesa que un grafo debe poseer ciertos nodos y lados conectando todos o algunos de estos nodos entre sí. La 'estructura' descrita por un grafo queda perfectamente fijada solamente por la especificación de nodos y lados. Por ejemplo, considérense los siguientes grafos 1 y 2 :

3 Con más precisión, sea un grafo $G=<V(G), L(G), I_{G}>. V(G)$ es el conjunto de nodos de $G$. $L(G)$ es el conjunto de lados de $G$. $I_{G}$ es una función de 'incidencia' que mapea a cada lado de $G$ un par de nodos de $G$. Sea, por ejemplo, $V(G)=\left\{n_{1}, n_{2}, n_{3}\right\}, L(G)=$ $\left\{l_{1}, l_{2}, l_{3}\right\}$ e $I_{G}$ con la siguiente asignación: $I_{G}\left(l_{1}\right)=\left\{n_{1}, n_{2}\right\}, I_{G}\left(l_{2}\right)=$ $\left\{n_{2}, n_{3}\right\}$ y $I_{G}\left(l_{3}\right)=\left\{n_{3}, n_{1}\right\}$ (Cf. Balakrishnan y Ranganathan, 2012, definición 1.2.1). Cuando los lados de un grafo están representando relaciones asimétricas, la función de incidencia asigna a cada lado un par ordenado de nodos. Un grafo conformado por relaciones asimétricas se denomina un "grafo dirigido".

4 Como bien ha hecho notar un evaluador anónimo de esta revista, al ser formulada la teoría de grafos en términos conjuntistas, resulta de inmediato que cualquier relación debe ser definida del modo usual propuesto, por ejemplo, por Kuratowski. Esto es, una relación binaria entre los elementos de conjuntos $A$ y $B$ es un conjunto de pares de elementos de $A$ y $B$. El 'par' de los objetos $\langle a, b>$ es el conjunto $\{\{a\},\{a, b\}\}$. Una relación se define, por lo tanto, como un conjunto de los relata, lo que hace automáticamente que las relaciones sean dependientes ontológicamente de los relata. 

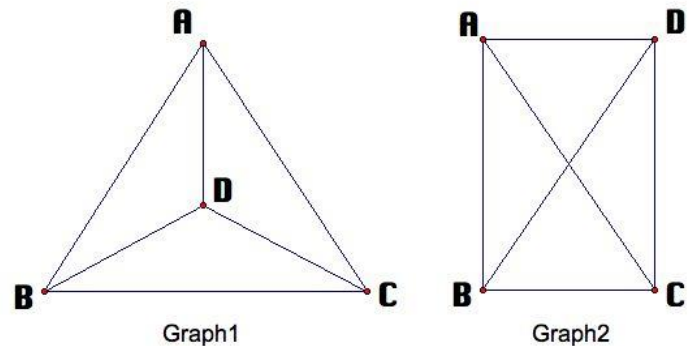

Estos dos grafos parecen poseer diferentes estructuras, pero no es así. Ambos poseen cuatro nodos $-A, B, C$ y $D-$ y exactamente los mismos lados: $\{A, B\},\{B, C\},\{A, C\}$, $\{A, D\} .\{B, D\}$ y $\{C, D\}$. Recuérdese que los lados se definen como conjuntos de nodos. En lo que concierne a teoría de grafos poseen la misma estructura, aunque la representación gráfica sea diferente. Una estructura diferente tendría un grafo también con cuatro nodos $A, B$, $C$ y $D$, pero con lados $\{A, B\},\{B, C\},\{C, D\}$ y $\{D, A\}$, cuya representación sería tal como la del grafo 2 , pero sin las diagonales entre los vértices del cuadrado ${ }^{5}$.

Algo importante que se hace visible con la perspectiva de teoría de grafos es que para constituir una estructura se requiere algo que cumpla las funciones de 'lado' y algo que cumpla las funciones de 'nodo'. La teoría de grafos, por sí misma, es perfectamente neutral respecto de cuál sea la

5 Dos grafos que poseen la misma estructura se dicen "isomórficos". Un isomorfismo entre grafos $G_{1 y} G_{2}$ se define como el par de funciones biyectivas $f_{1}$ y $f_{2}$, tal que $f_{1}: V\left(G_{1}\right) \rightarrow$ $V\left(G_{2}\right) ; f_{2}: L\left(G_{1}\right) \rightarrow L\left(G_{2}\right)$ y con la propiedad de que $I_{G 1}(D)=\left\{n_{1}\right.$, $\left.n_{2}\right\}$ si y sólo si $I_{G 2}\left(f_{2}(D)=\left\{f_{1}\left(n_{1}\right), f_{1}\left(n_{2}\right)\right\}\right.$ (cf. Balakrishnan y Ranganathan, 2012, definición 1.2.9). Un isomorfismo de un grafo en sí mismo se denomina un "automorfismo". La 'estructura' de un grafo puede ser definida como aquello que se preserva por isomorfismos. 
naturaleza de lo que cumpla estas funciones, pero algo debe hacerlo. Esto es, un requerimiento necesario para que exista algo que merezca el nombre de "estructura" es que: (i) debe haber relaciones que la conforman, y (ii) debe haber algo que esté conectando entre sí estas relaciones. Si se consideran los grafos 1 y 2 arriba, su estructura está conformada porque es el nodo $D$ el que está relacionado con $A, B$ y $C$. Por supuesto, es indiferente cómo sea designado este nodo, pero sí es indispensable que exista algo que sea aquello que está relacionado con algo que cumpla las mismas funciones que $A$, y esa misma entidad debe estar relacionada con algo que cumpla las funciones que cumple el nodo $B$, y esa misma entidad debe estar relacionada con algo que cumpla las funciones que cumple el nodo $C$. Una colección de nodos que no estén relacionados entre sí no conforma propiamente una estructura. Tampoco conforma una estructura una colección de relaciones que no estén vinculadas por ser las relaciones entre los mismos nodos.

Este requerimiento de 'nodos' para una estructura está asociado a otro requerimiento tradicional. Ha sido habitual sostener que toda relación depende de sus relata. Al menos desde Aristóteles en adelante se ha supuesto que las relaciones son 'accidentes' cuyo ser depende ontológicamente del ser de las sustancias que está conectando (Categorias, 1b30-2a1, 6b3-8). Este tipo de objeción se ha repetido muchas veces contra las posiciones estructuralistas (cf. Cao, 2003; Chakravartty, 2003; Morganti, 2004; Psillos, 2006; Briceño y Mumford, 2016), tal como se ha indicado arriba. Es más, dada la preeminencia ontológica concedida a las sustancias objetos particulares que, si son sensibles, deben ocupar una región espacial conectada y continua- las relaciones resultan metafísicamente sospechosas. En efecto, ¿qué tipo de existencia podría tener algo que 'está' en más de una sustancia? ¿Cuál sería su localización? No es raro que varias 
veces en la historia se las haya tratado de eliminar por sus 'fundamentos'6. Lo que se va a sostener más abajo es que se puede respetar el requerimiento de 'nodos' para conformar una estructura, pero sin necesidad de introducir 'objetos' como aquello que cumpla las funciones de tal. Hay una diferencia, entonces, entre el requerimiento de que toda estructura requiere nodos y el requerimiento de que toda estructura -que ha de estar constituida por relacionesrequiere relata, esto es, objetos relacionados.

Las estructuras físicas propuestas por el estructuralismo óntico deben ser 'fundamentales'. No habría problema en admitir estructuras físicas para quien piense que hay ciertos objetos físicos de un carácter ontológicamente básico. Estas estructuras, sin embargo, serían ontológicamente derivativas pues estarían conformadas por las relaciones entre los objetos físicos básicos. Es característico del estructuralismo óntico, sin embargo, la suposición de que las estructuras de que se trata no dependen de objetos más básicos. Esto es lo que ha generado la mayoría de las objeciones contra el estructuralismo. Hay varias formas en que puede ser entendida la 'prioridad ontológica'. De un modo general, se puede decir que $x$ es 'ontológicamente prioritario' respecto de $y$ porque (i) y funda a (grounds) $x$, o bien porque (ii) $x$ depende de $y$. La 'fundación' (grounding) y la 'dependencia' se van a considerar aquí como nociones primitivas. La primera puede ser caracterizada como la suficiencia constitutiva para el ser de algo (cf. Correia y Schnieder, 2012). La segunda, en cambio, puede ser caracterizada como algo constitutivamente necesario para el ser de algo (cf. Fine, 1995). En efecto, si $x$ está fundado en $y$, entonces es necesario que: si $y$ existe, $x$ exista también. La

${ }^{6}$ Para un panorama histórico de los tratamientos de las relaciones en la tradición filosófica aristotélica, cf. Brower, 2016. Una versión reciente de la eliminación de una relación por sus fundamentos en Campbell, 1990, 97-133. 
existencia de $y$ es todo lo que se requiere para la existencia de $x$. Al contrario, si $x$ depende de $y$, entonces es necesario que: si $x$ existe, $y$ exista. Esto es, la existencia de $x$ incluye como parte de su esencia la existencia de $y$, de manera que $\sin y, x$ no existiría. Estas dos relaciones se van a suponer como relaciones irreflexivas, asimétricas y transitivas entre entidades de cualquier categoría ontológica, aunque más abajo se va a discutir la alternativa de postular cierta dependencia simétrica entre objetos y relaciones. Cuando se consideran aquí estructuras ontológicamente 'fundamentales' es porque las relaciones que las constituyen ni están fundadas en sus relata, ni dependen ontológicamente de sus relata. Lo que ha estado en cuestión, sin embargo, es la dependencia de las relaciones en sus relata, pues esto es lo que tradicionalmente se ha supuesto en la tradición filosófica? ${ }^{7}$.

Uno de los aspectos más notorios de una estructura física es que debe ser una estructura concreta y particular. Sus constituyentes deben ser también particulares y concretos o, por lo menos, deben incluir por lo menos algún constituyente concreto y particular. Lo que está siendo sostenido por el estructuralista óntico es que cualquier objeto físico macroscópico ordinario está constituido por estructuras. Aunque uno pueda admitir, por ejemplo, que hay objetos como planetas o galaxias, tales objetos no son fundamentales, sino que se encuentran fundados en otras

\footnotetext{
7 Más precisamente, lo que se ha supuesto es que toda relación sea interna o externa- es dependiente ontológicamente de sus relata. En el caso de las relaciones internas, además, estas están también fundadas en sus relata. Como se sabe, la noción de 'relación interna' ha sido entendida como una relación fundada en la naturaleza intrínseca de sus relata -esto es, en las propiedades intrínsecas de esos relata, sean o no esenciales para ellos- o simplemente fundada en sus relata - esto es, como esencial para estos.
} 
entidades ontológicamente más básicas. Las entidades físicamente fundamentales serían estructuras. Si los planetas y las galaxias son entes concretos, las estructuras que los constituyen deben ser concretas también. Esta característica de las estructuras postuladas por los estructuralistas ónticos marca una diferencia grande respecto del estructuralismo matemático. Una estructura matemática es típicamente algo abstracto que puede estar instanciado o ejemplificado en diferentes colecciones de objetos. Una estructura matemática es un universal, en cambio, una estructura física, de aquellas postuladas por el estructuralismo óntico, es un particular. Una cuestión diferente es que se haga uso de alguna estructura matemática para representar las características de tipos de estructuras físicas. El estructuralismo óntico no es una posición acerca de nuestras representaciones de la realidad física, sino sobre esa realidad física.

Ha existido una controversia filosófica acerca de cómo debería analizarse correctamente la distinción entre lo concreto y lo abstracto (cf. para una presentación de conjunto, Cowling, 2017, 69-105). Uno podría sostener que, si no hay claridad acerca de esta distinción, no es claro tampoco qué es lo que se esté requiriendo de una estructura física al indicar que debe ser una entidad concreta (cf. Lewis, 1986, 81-86). Sucede en este caso como en otras áreas de discusión filosófica que la ausencia de un análisis a satisfacción de todo el mundo se confunde con nuestra ignorancia acerca del contenido de tal concepto. El fracaso de los intentos de analizar algo no son evidencia de que el analysandum sea incoherente, o de que no tengamos alguna comprensión de él ${ }^{8}$. Parece perfectamente claro que los

8 Es más, la única forma en que podría justificarse un contraejemplo a un análisis propuesto es presuponiendo nuestra comprensión del analysandum. Por ejemplo, supóngase que se ofrece un análisis del concepto $C$. Sea el analysans $C^{*}$. Si el análisis 
universales son paradigmáticamente entidades abstractas, mientras que los objetos particulares son paradigmáticamente entidades concretas. Todo lo que se requiere para los propósitos de este trabajo es aceptar esos casos paradigmáticos de aplicación de los conceptos de 'ser abstracto' y de 'ser concreto', dejando a un lado la adjudicación de casos dudosos en los que nuestras intuiciones no sean suficientes para arrojar un veredicto en un sentido $\mathrm{u}$ otro. A estas intuiciones pueden agregarse algunos requerimientos adicionales $-\mathrm{si}$ se quiere, como estipulaciones acerca de qué se pretende entender por "concreto" y "abstracto" (cf. Cowling, 2017, 70-71): (i) algo es concreto si y sólo si no es abstracto, y es abstracto si y sólo si no es concreto'; (ii) todo es, o concreto o abstracto;

es correcto, entonces resulta una verdad necesaria a priori que $[C$ $\leftrightarrow C^{*}$. Un contra-ejemplo a este análisis, entonces, será un caso en que algo cae bajo $C$ y no cae bajo $C^{*}$, o un caso en que algo no cae bajo $C$ y cae bajo $C^{*}$. Pero para poder llegar a saber de alguno de estos contra-ejemplos se requiere, por lo tanto, poder juzgar correctamente que algo cae o no cae bajo C. Pero para esto se requiere comprender en qué consiste ser un $C$.

9 Algunos han rechazado que el carácter 'abstracto' o 'concreto' de una entidad sean contradictorios entre sí. Lo usual, en efecto, ha sido suponer que algo es abstracto si y sólo si no es concreto y viceversa. Para estos filósofos, en cambio, una misma entidad puede ser concreta en algunos mundos posibles en los que existe y no concreta en otros. El carácter de 'abstracto', en cambio, no puede ser contingente para una entidad. Si algo es 'abstracto', lo es necesariamente. Por lo tanto, las distinciones entre abstracto/no-abstracto y entre concreto/no-concreto se encuentran en planos distintos, comoquiera que sean entendidas finalmente las nociones de 'abstracto' y de 'concreto'. No se va a entrar aquí a discutir esta forma de plantear la distinción, pues tiene que ver con requerimientos teóricos del 'necesitismo', esto es, de la tesis de acuerdo a la cual es necesario que todo objeto exista necesariamente (cf. Williamson, 2013, 7). En efecto, para el 
(iii) si algo es concreto, entonces es necesariamente concreto, y si algo es abstracto, entonces es necesariamente abstracto; (iv) una fusión mereológica una de cuyas partes sea concreta, es una entidad concreta ${ }^{10}$. Una estructura, entonces, aunque pueda incluir entidades abstractas tales como universales relacionales, será también un ente concreto.

La cuestión podría dejarse en este punto si no fuese porque, como parte del debate general acerca del estructuralismo óntico, se ha planteado que ninguna relación es concreta (cf. Briceño y Mumford, 2016, 202-203). De acuerdo a Sebastián Briceño y a Stephen Mumford puede admitirse la idea de una propiedad monádica particular y concreta, pero no la de una relación particular y concreta. Una 'estructura', cualquiera que sea, debe estar conformada por relaciones universales. Una ontología que sea 'puramente relacional' estará postulando nada más que estructuras matemáticas. El motivo aducido para rechazar cualquier relación concreta es que no podemos hacer una demostración indexical a una relación particular -si hubiese tal cosa- como lo podemos hacer para una cualidad particular. Lo enuncian vívidamente de este modo:

Podemos admitir, por ejemplo, que hay una instancia concreta de la propiedad 'verde' y 'con-forma-de-hoja' cuando apuntamos a esa

necesitista aunque todos los objetos son necesarios, no en todos los mundos esos objetos son 'concretos'. Si 'ser concreto' fuese el contradictorio de 'ser abstracto', y 'ser abstracto' es un carácter necesario de aquello que lo es, no sería inteligible que objetos pudiesen ser 'contingentemente concretos'.

10 No es prudente establecer una estipulación semejante para conjuntos, pues estos son -de por sí- casos menos daros para la aplicación de los conceptos 'concreto' y 'abstracto', tal como se indicará más abajo. 
hoja. Ahí la tiene: ahí hay una clara porción de realidad, justo en frente de su campo visual, que es verde y con forma de hoja, y -hasta donde alcanzamos a ver- no tiene carácter relacional (...) Ahora trate de hacer lo mismo con una relación. Para empezar, trate de apuntar a una porción de realidad en donde exista algo como <__ es más alto que __ $>$ o $<$ _ está causando que __>, pero sin apuntar a algo concreto que tenga un carácter no relacional. (Briceño y Mumford, 2016, 203).

Este tipo de intuiciones son las que han estado motivando por siglos la desconfianza hacia las relaciones como entidades de pleno derecho. Hay varias cosas que advertir acerca de esta alegación. En primer lugar, no parece que la localización espacio-temporal pueda ser admitida como el criterio para analizar en qué consiste el carácter concreto de algo concreto. En segundo lugar, Briceño y Mumford se han apresurado para desestimar la posibilidad de hacer demostraciones indexicales a relaciones. Parece más bien que, si es posible 'apuntar' a colores o a formas, también es posible apuntar a relaciones. Convendrá considerar estos puntos con un poco más de detalle para disipar algunos de los cuestionamientos que han hecho ontológicamente sospechosas a las relaciones.

Entre las formas en que se ha pretendido analizar la noción de 'concreto' -y de su contradictorio, lo 'abstracto'se ha indicado que algo es concreto si y sólo si está localizado espacio-temporalmente. Algo con localización espacio-temporal sería algo a lo que se podría hacer una demostración indexical. También se ha pretendido analizar la noción de 'concreto' sosteniendo que algo es concreto si y sólo si puede entrar en interacciones causales, o es de existencia contingente, o puede tener duplicados cualitativamente indiscernibles. Todas estas formas de 
analizar la distinción concreto/abstracto, sin embargo, se han encontrado con el problema de entidades que, aunque parecen de entrada de carácter abstracto, 'incluyen' entidades concretas y heredan parte de sus características. En principio, tantos los conjuntos, como las proposiciones y las propiedades universales parecen entidades abstractas. Además de conjuntos 'puros' -que están construidos por operaciones conjuntistas sobre el conjunto vacío- hay conjuntos 'impuros' que incluyen, por ejemplo, objetos particulares concretos, tal como el conjunto singleton \{Sócrates\}. Parece haber proposiciones singulares que incluyen objetos particulares concretos, tales como la proposición de que Sócrates es un hombre. Parece haber propiedades universales no cualitativas que incluyen también objetos particulares concretos, tal como la propiedad de ser diferente de Sócrates. Estas entidades, por lo tanto, parecen contingentes, pues dependen ontológicamente de Sócrates, que es una entidad contingente. Parece que -al menos en algunos casospueden heredar la localización espacio-temporal de Sócrates ${ }^{11}$. Parece que - también en algunos casos- estas entidades pueden entrar en relaciones causales si es que Sócrates puede hacerlo ${ }^{12}$. Y parece, en fin, que la inclusión de objetos particulares permite construir conjuntos, proposiciones y propiedades cualitativamente indiscernibles entre sí. Si Sócrates es indiscernible cualitativamente de Sócrates*, entonces parece que los conjuntos \{Sócrates\} y

11 Por lo demás, los defensores de universales inmanentes -esto es, universales que sólo existen si es que poseen instancias- han sostenido de manera general que los universales están localizados en la localización de sus instanciaciones.

12 También se ha sostenido de manera general que los universales sí entran en interacciones causales, pues toda interacción causal en la que entre un objeto estará fundada en qué universales instancie. 
\{Sócrates*\} serán también indiscernibles, así como las propiedades de ser diferente de Sócrates y ser diferente de Sócrates*13. La posibilidad de hacer una demostración indexical no parece, por lo tanto, un test seguro para determinar si algo es o no concreto ${ }^{14}$.

Sucede, por otra parte, que no parece imposible hacer una demostración indexical a una relación. Tendría que tratarse de una relación particular, un tropo relacional. Piénsese cómo se podría hacer una demostración indexical a una forma o a un color. Las demostraciones indexicales permiten seleccionar aquello que se intersecta con la línea que se proyecta siguiendo la dirección del dedo índice de quien indica. Aquello con lo que se intersecta una línea es estrictamente un punto. Derivativamente, uno puede decir que se intersecta con una línea por intersectarse con un punto de esa línea. Derivativamente, uno puede decir que se intersecta con una superficie por intersectarse con un punto de esa superficie. Si se puede hacer demostraciones indexicales a un color o una forma es porque -también de manera derivativa- se puede suponer que lo indicado es el color de una superficie a la que se indica, o es una forma de la superficie o del cuerpo al que se indica. Un cuerpo exige cierta distensión entre las partes de ese cuerpo, esto es, requiere la existencia de relaciones de distancia entre tales

13 A estos intentos puede agregarse el de Hoffman y Rosenkrantz (1994, 182-187), quienes sostienen que algo concreto es algo que pertenece a una categoría que posiblemente induye entidades con partes espaciales y/o temporales. Esta propuesta adolece de los mismos problemas que las anteriores. Por ejemplo, es discutible si las partes espaciales de Sócrates son partes también del conjunto \{Sócrates\}. Si se admite tal cosa, los conjuntos pasan a ser entidades concretas de manera general.

14 Por lo demás, Dios o cualquier ángel son entidades concretas de haberlos. ¿Qué demostración indexical podría hacerse de Dios? 
partes. ¿Por qué no podría hacerse una demostración indexical a tal distención en sí misma? Si se puede hacer una indicación al color de las superficies de un cuerpo no veo ningún inconveniente para indicar las relaciones entre las partes de ese mismo cuerpo por las que el cuerpo en cuestión es un cuerpo en primer lugar. Estas relaciones son tan particulares como el cuerpo que hacen posible. No parece haber problemas, entonces, para concebir tropos relaciones de carácter particular y concreto.

Se pueden ahora enunciar de manera general los requerimientos para una estructura concreta fundamental que deberán tenerse presentes en la discusión que sigue y que resultan del examen que se ha hecho en esta sección:

[Requerimiento nodal]

[Requerimiento de prioridad]

[Requerimiento de concreción]
Las estructuras requieren relaciones y nodos que vinculen entre sí tales relaciones.

Las relaciones no deben ser dependientes de sus nodos.

Las estructuras deben ser particulares concretos.

\section{$\int$ 2. ONTOLOGÍAS TRADICIONALES Y ESTRUCTURAS CONCRETAS}

Una de las dificultades principales que ha enfrentado el estructuralismo óntico es que casi ninguna de las teorías tradicionales acerca de la naturaleza de los particulares parece dejar espacio para estructuras concretas fundamentales, del modo en que se ha explicado en la sección anterior. Estas estructuras concretas deben estar 
constituidas por relaciones entre algo que debe cumplir las funciones de un 'nodo', según se ha indicado. Las grandes concepciones acerca de la naturaleza de un particular han sido las ontologías de sustratos y las ontologías de cúmulos o haces de propiedades. Esto es, hay por una parte una larga tradición que ha sostenido que un particular debe estar constituido por un sustrato o particular delgado y por las propiedades que este particular instancie. Otra gran tradición ha pretendido dispensarse de la necesidad de postular un sustrato y ha sostenido que los particulares son nada más que colecciones de propiedades que satisfacen ciertas condiciones. Se verá que ninguna de estas dos grandes tradiciones parece ofrecer una ontología suficientemente adecuada para los requerimientos del estructuralista óntico, al menos, sin modificaciones importantes.

Considérense, en primer lugar, las ontologías de sustratos. Es característico de estas ontologías que se postula algo, un 'particular delgado' o 'particular desnudo' que cumple la función de ser aquello en que están instanciadas las propiedades del objeto. Este sustrato, por sí mismo, no posee ninguna propiedad. El objeto considerado globalmente, con el sustrato y todas sus propiedades se ha denominado 'particular grueso'. Algunas teorías de sustratos han postulado propiedades universales para constituir a los particulares gruesos (cf. Armstrong, 1978a, 102-125; 1997, 95-127). En estas concepciones el sustrato, junto con ser aquello que unifica a un objeto y aquello en lo que las propiedades están instanciadas, es aquello que contribuye la 'particularidad' al objeto particular, pues las propiedades son todas ellas universales. Un estado de cosas es particular por estar constituido por un sustrato individual, aunque el universal o los universales que también lo integran no lo sean. Otras teorías de sustratos, sin embargo, han postulado propiedades particulares o tropos para constituir el particular grueso (cf. Martin, 1980; 
Heil, 2003, 169-192; 2012, 12-52). En estas concepciones los sustratos no cumplen la función de contribuir la particularidad del objeto particular, pues tanto el sustrato como sus propiedades son particulares ${ }^{15}$. Para lo que interesa aquí, es característico de cualquiera de estas ontologías que los objetos particulares tienen como constituyente básico a un sustrato. En las teorías de sustratos y tropos, el sustrato es, además, parte de las condiciones de identidad de tales tropos. Una propiedad particular, en efecto, no sería la propiedad particular que es si no estuviese instanciada en un sustrato específico. Desde esta perspectiva, las propiedades son ontológicamente dependientes de los sustratos que determinan. En las teorías de sustratos y universales, las propiedades no dependen ontológicamente de los sustratos que las instancian ${ }^{16}$, pero sigue resultando que el objeto particular grueso depende de su sustrato, pues sin él no existiría de ningún modo. Los estados de cosas que involucren a tal objeto serán también, por los mismos motivos, ontológicamente dependientes del sustrato del objeto.

En la perspectiva de estas teorías, una relación es una propiedad como cualquier otra, sólo que cada instanciación particular se produce en una pluralidad de objetos. Una estructura debe ser, por lo tanto, un estado de cosas complejo de estar una pluralidad de sustratos bajo ciertas relaciones entre sí. Hay diferencias entre las teorías que

15 Hay también concepciones en las que se postulan sustratos, propiedades universales y tropos. Cf. Lowe, 2006, 3-86. Estas ontologías ofrecen las mismas dificultades que las que se explicarán para teorías de sustratos más tradicionales.

$16 \mathrm{Si}$ los universales de que se trata son 'inmanentes' o 'aristotélicos' (cf. Armstrong, 1978a, 64-76; 113-116; 1997, 3843), su existencia depende de tener al menos una instanciación en algún particular. No dependerían, en este caso, rígidamente de este sustrato, sino de algún u otro sustrato que los instancie. 
postulan universales y las que postulan tropos en este punto, pues para las teorías de sustratos y universales, una estructura debe ser entendida como un estado de cosas complejo constituido por una pluralidad de sustratos y una pluralidad de relaciones universales instanciadas en tales sustratos. La estructura debe ser una entidad concreta y particular, tal como se ha explicado. En este caso, el carácter particular y concreto de la estructura ha sido contribuido exclusivamente por los sustratos integrantes. En las ontologías de sustratos y tropos, en cambio, una estructura debe ser entendida como una pluralidad de sustratos y una pluralidad de tropos relacionales que se instancian en tales sustratos ${ }^{17}$. Sustratos y tropos relacionales son ambas entidades particulares concretas. El problema que tienen estas ontologías para el estructuralismo óntico es que, bajo cualquiera de estas alternativas, las estructuras son ontológicamente dependientes de sustratos, esto es, se viola el Requerimiento de prioridad. Las ontologías de sustratos, entonces, parecen validar completamente la idea de que las relaciones dependen de sus relata.

Una segunda gran familia de ontologías, sin embargo, se dispensa de postular sustratos. Si las ontologías de sustratos se han mostrado inadecuadas para hacer inteligible una estructura física fundamental concreta, tal vez las ontologías sin sustratos ofrezcan la forma de hacerlo. Un examen de las principales ontologías de cúmulos de propiedades, sin embargo, mostrará que la situación aquí está lejos de ser cómoda. En muchos casos, ni siquiera se puede hacer

17 Las concepciones que postulan sustratos, universales y tropos también deben verse como tratando a las estructuras de este modo pues, aunque hay relaciones universales de las que los tropos relacionales son instanciación, la estructura concreta está constituida por los sustratos y los tropos relacionales concretos entre ellos. 
inteligible alguna estructura no fundamental, pues se hace difícil entender cómo puede haber relaciones entre objetos. En estas teorías los objetos se reducen a pluralidades de propiedades. La forma estándar de entender tales propiedades es como tropos (cf. Williams, 1953a, 1953b; Campbell, 1981, 1990; Denkel, 1996; Maurin, 2002; Ehring, 2011), aunque también algunos han presentado teorías de cúmulos de universales (cf. O'Leary-Hawthorne y Cover, 1998). Las teorías de cúmulos de universales se han visto mucho más problemáticas, por lo que no se van a considerar en esta discusión (para una discusión crítica, cf. por ejemplo, Armstrong, 1978a, 89-101). En las teorías de sustratos, la unidad del objeto particular se explica muy fácilmente porque hay una única entidad en cada objeto, un sustrato, que instancia todas las propiedades del objeto. En las teorías de cúmulos la unidad del objeto particular debe explicarse mediante otros mecanismos. Se han presentado dos grandes alternativas para concebir la naturaleza de los tropos que conforman un cúmulo que serán examinadas por orden. Una tradición -que ha sido dominante entre los defensores de tropos del siglo pasado- ha sostenido que los tropos son entidades independientes entre sí, esto es, que ningún tropo hace necesaria la existencia o inexistencia de otros tropos. Otra tradición, en cambio, ha sostenido que los tropos son entidades ontológicamente dependientes unas de otras.

En la tradición de los tropos independientes entre sí, la unidad del objeto particular se ha tratado de explicar fundamentalmente por la 'concurrencia' en la misma región espacio-temporal (cf. Williams, 1953a, 1953b; Campbell, 1981, 1990). Esto es, un objeto debe identificarse con la fusión mereológica de todos y sólo los tropos que ocupan la misma región del espacio-tiempo. En esta perspectiva, la unidad de un objeto no resulta de ningún hecho misterioso. Los tropos tienen localización. El hecho de que un tropo ocupe una región no excluye que otros tropos también lo 
hagan. Un tropo de masa, por ejemplo, puede concurrir con un tropo de carga electromagnética. Si se considera una región cualquiera del espacio-tiempo, existirá una y sólo una suma de todos los tropos que ocupan exactamente esta región. Tal suma mereológica será un objeto. A pesar de su elegancia, esta concepción resulta muy inadecuada para hacer inteligibles estructuras en el sentido que nos interesa. Una estructura requiere una pluralidad de relaciones y de entidades relacionadas. Considérese cómo podría haber una relación entre dos objetos diferentes en esta perspectiva. Una relación es aquí un tropo como cualquier otro, pero poliádico. Si se trata de una relación $r$ entre $x_{1}$ y $x_{2}$, se requiere que sea parte del cúmulo en que consiste $x_{1} \mathrm{y}$ también parte del cúmulo en que consiste $x_{2}$. Recuérdese que un objeto se identifica con una fusión mereológica de tropos concurrentes entre sí. La única forma en que un tropo, cualquiera sea su naturaleza, sea parte de un cúmulo es estando localizado exactamente en la misma región espacio-temporal que todos los restantes tropos del cúmulo. La única forma, por lo tanto, en que el tropo relacional $r$ podría conectar a $x_{1}$ y a $\chi_{2}$ sería si $r$ estuviese localizado exactamente en la región espacio-temporal en que está localizado $x_{1}$ y estuviese localizado exactamente en la región espacio-temporal en que está localizado $x_{2}$. Pero para esto se requeriría que la región espacio-temporal que ocupa $x_{1}$ fuese exactamente la misma región espaciotemporal que ocupa $x_{2}$. Pero si fuese así, $x_{1}$ y $x_{2}$ serían el mismo cúmulo de tropos. Pero si son el mismo cúmulo de tropos, entonces es absurdo pensar que $x_{1}$ y $x_{2}$ tienen entre sí la relación $r$. Difícilmente podría ser inteligible una estructura física desde esta perspectiva si ni siquiera es inteligible una relación ${ }^{18}$.

18 No es extraño, entonces, que defensores de esta concepción hayan querido eliminar las relaciones. Campbell, en particular, sostiene que debe admitirse un único objeto que sería un ámulo 
Existe otra tradición para entender la naturaleza de los tropos en que estos son todos ontológicamente dependientes unos de otros ${ }^{19}$. Un ejemplo muy característico de esta posición es la ontología propuesta por Edmund Husserl en la III Investigación lógica (cf. Husserl, 1900/1901, III Investigación, JS 21-24; Simons, 1982). En esta teoría un todo en el sentido 'pregnante' es un todo conformado por todos y sólo los tropos que son dependientes mutuamente entre sí. Esto es, es de la esencia de cada uno de los tropos que está constituyendo un cúmulo existir conformando precisamente ese cúmulo con todos los restantes tropos que lo constituyen. La unidad del objeto particular se consigue ahora con las dependencias mutuas entre los tropos que conforman el cúmulo. ¿Cómo debería entenderse una estructura desde esta perspectiva? Para la existencia de una estructura se requiere una pluralidad de relaciones y una pluralidad de entidades relacionadas. Supóngase que hay un tropo relacional $r$ entre los objetos $x_{1}$ y $x_{2}$. Para que un tropo sea parte de un cúmulo debe ser dependiente ontológicamente de todos los restantes tropos de ese cúmulo. La única forma en que el tropo relacional $r$ podría conectar a $x_{1}$ y $x_{2}$ es si fuese ontológicamente dependiente de todos los tropos de $x_{1}$ y si fuese ontológicamente dependiente de todos los tropos de $x_{2}$. Sucede, sin embargo, que la dependencia ontológica es transitiva. Si $r$ depende de un tropo de $x_{1}$, y si un tropo de $x_{2}$ depende de $r$, entonces ese tropo de $x_{2}$ depende del

de grandes tropos que ocuparían la totalidad del espacio-tiempo. Cada uno de los tropos de este gran ámulo correspondería a las fuerzas físicas fundamentales. Cf. Campbell, 1990, 135-155.

19 También se ha entendido a los tropos como entidades dependientes de otras en las concepciones que postulan tropos y sustratos. En buena parte de la historia de la filosofía los tropos se han introducido como 'acidentes' dependientes ontológicamente de las sustandias a las que están determinando. 
tropo de $x_{1}$. Recuérdese que un todo 'pregnante' está conformado por todos y sólo los tropos mutuamente dependientes entre sí. El tropo relacional $r$ debe ser dependiente de todos los tropos de $x_{1}$ y de $x_{2}$, así como todos los tropos de $x_{1}$ y $x_{2}$ deben ser dependientes de $r$. Resulta, entonces, que en una situación como la descrita todos los tropos de $x_{1}$ y de $x_{2}$ serían mutuamente dependientes. Pero, entonces, no son dos objetos diferentes sino el mismo objeto. Entonces, parece ininteligible que $x_{1}$ y $x_{2}$ estuviesen relacionados por $r$. Sucede aquí lo mismo que para el caso de los tropos independientes entre sí. No es inteligible una estructura física, porque ni siquiera es inteligible una relación entre entidades físicas.

Una variación de la teoría de los todos 'pregnantes' de Husserl es la teoría 'nuclear' propuesta por Peter Simons (cf. Simons, 1994). La teoría nuclear permite acomodar relaciones y algunas formas de estructura física, pero genera las mismas dificultades que se presentan en las ontologías de sustratos. En esta concepción la unificación del objeto particular también se efectúa por dependencias ontológicas mutuas entre tropos, pero estas dependencias permiten diferenciar dos estratos en el cúmulo: un núcleo y una periferia. El núcleo de un cúmulo está constituido por tropos todos ellos mutuamente dependientes entre sí tal como sucede para un todo 'pregnante' husserliano. Se trata de las propiedades esenciales para el objeto conformado con ese cúmulo, pues el cúmulo no podría existir sin alguno de los tropos nucleares. Junto al núcleo se encuentra la 'periferia' que está constituida por tropos ontológicamente dependientes de los tropos del núcleo, pero sin que los tropos del núcleo sean ontológicamente dependientes de los tropos periféricos. Se trata de propiedades accidentales para el objeto de que se trate, pues el núcleo seguiría existiendo, aunque careciese de algunos de los tropos periféricos que posee de hecho. En esta concepción serían admisibles relaciones entre objetos como constituyentes de 
varias periferias. Un tropo relacional $r$ puede estar conectando los objetos $x_{1}$ y $x_{2}$ al ser parte de la periferia de $x_{1}$ y parte de la periferia de $x_{2}$. Esto hace que $r$ sea dependiente de todos los tropos del núcleo de $x_{1}$ y de todos los tropos del núcleo de $x_{2}$, pero los tropos de esos núcleos no dependen de $r$. De este modo, no se sigue aquí el resultado desastroso que aparece respecto de los todos 'pregnantes' husserlianos ${ }^{20}$. Se puede apreciar, entonces, que la teoría nuclear está en mucho mejor pie que las anteriores teorías de cúmulos de tropos para hacer inteligibles estructuras, pero -desgraciadamente- no en mejor pie que las ontologías de sustratos. Las relaciones aquí son inteligibles como entidades dependientes de aquello que está siendo relacionado. A diferencia de las ontologías de sustratos, los relata en este caso no son sustratos, sino cúmulos nucleares. Como en la teoría nuclear los núcleos son la esencia de un objeto, lo que sucede aquí, por lo tanto, es que sigue valiendo la idea de que las relaciones son dependientes de sus relata, esto es, se viola el Requerimiento de prioridad.

\section{§3. Cúmulos estructurales}

Por lo que se ha podido revisar hasta este momento ninguna ontología se ha mostrado adecuada para hacer inteligibles 'estructuras' del tipo que los estructuralistas ónticos quieren proponer, esto es, como pluralidades fundamentales de relaciones y 'nodos' conectados entre sí,

20 Por supuesto, si se quisiese establecer una relación entre los núdeos de dos o más objetos se seguiría la identificación de esos objetos, tal como se ha explicado arriba, pues tal relación debería ser parte de cada uno de ellos. En la medida en que las relaciones sean periféricas, el colapso de los relata de una relación se bloquea. 
de carácter concreto y particular. Hay, sin embargo, varias formas de acomodar una ontología de cúmulos de tropos para ofrecer estructuras físicas concretas. Estos cúmulos de tropos son los que se denominan aquí "cúmulos estructurales". De acuerdo a lo que se ha explicado, el estructuralista requiere la postulación de estructuras de carácter concreto. Lo más razonable para esto es pensar en alguna forma especial de cúmulo de tropos. Si uno hace apelación a universales para conformar estructuras concretas se requiere de algo que efectúe la contribución de 'particularidad', lo que normalmente realiza un sustrato, tal como se ha visto. Pero la introducción de sustratos inmediatamente invierte la relación de dependencia buscada, pues aquello que hace de 'nodo' en la estructura no será dependiente de las relaciones que la constituyen, sino que tales relaciones $-y$ la estructura completa con elloserán dependientes de los sustratos. Esto es, la satisfacción de los requerimientos de Prioridad y Concreción exigen pensar en alguna forma de cúmulo de tropos relacionales.

Ha sido usual en la historia de la filosofía pensar en los tropos como propiedades monádicas y no como relaciones (cf. para una revisión, Mertz, 1996, 83-183). Los ejemplos de tropos normalmente citados son propiedades como el color o la forma, los que no parecen tener un carácter relacional. Si uno va a admitir relaciones en la ontología, sin embargo, estas relaciones deben entenderse como cualquier otra propiedad. Si uno admite tropos en la ontología de manera general, las relaciones serán también tropos. Una estructura concreta será, por lo tanto, un plexo de relaciones particulares. Como estas relaciones son tropos relacionales, una estructura debe entenderse como un tipo de cúmulo de tropos. Por ejemplo, si el espacio-tiempo, tal como viene descrito por la teoría de la relatividad general, va a entenderse desde una perspectiva estructuralista, no será un conjunto de puntos a los que se le asignan luego ciertas propiedades. Tampoco será una colección de 
relaciones entre objetos previamente dados con cierta naturaleza intrínseca. El espacio-tiempo se constituye por un plexo de relaciones de distancia con ciertas características topológicas. Tales relaciones de distancia no son relaciones universales de distancia. Se trata de entidades concretas, tan concretas como lo es cualquier distancia espacio-temporal concreta entre dos eventos.

La satisfacción de los requerimientos de Prioridad y Concreción debe ser acompañado por la satisfacción del Requerimiento nodal, esto es, debe existir algo que cumpla las funciones de 'nodo', pero que dependa ontológicamente de las relaciones que conforman la estructura y no al revés. En una ontología de sustratos no habría ninguna dificultad para admitir estructuras físicas concretas, pero estas estructuras no serían fundamentales. Se trataría de estructuras constituidas por relaciones entre sustratos físicos cuya existencia debería ser ontológicamente prioritaria. Precisamente lo característico de un planteamiento estructuralista es que en el nivel fundamental no hay objetos o sustratos, sino relaciones. Este es, quizás, el punto más importante para hacer inteligible un cúmulo estructural. Parece haber por lo menos tres formas para acomodar cúmulos estructurales con las restricciones indicadas que pasarán a discutirse a continuación.

\section{$\int 3.1$. Relaciones nodales}

Una primera forma de comprender una estructura concreta fundamental es como una colección de tropos relacionales de primer orden y, luego, tropos relacionales de segundo orden que cumplen las funciones de 'nodos'. En vez de pensar en los nodos como objetos que están siendo relacionados -lo que invita inmediatamente a contemplar las relaciones desde la perspectiva de una ontología de sustratos- se pueden concebir los nodos de una estructura 
como relaciones entre relaciones. En efecto, la función teórica que satisface un nodo es 'conectar' o 'vincular' dos relaciones, por ser aquello que, al mismo tiempo, está en una o varias relaciones con otros nodos. La forma en que se expresa esta función es precisamente designando relaciones. Un antecedente importante de esta alternativa es la propuesta de Anna-Sofia Maurin para explicar la unidad de un cúmulo de tropos independientes entre sí (cf. Maurin, 2002, 163-166). Dadas las limitaciones de las soluciones tradicionales para esta cuestión, tal como se han indicado arriba, Maurin ha sostenido que la unidad de un cúmulo debe estar fundada en un tropo especial de 'coinstanciación'. Este tropo es relacional y tiene la peculiaridad de que es ontológicamente dependiente de los restantes tropos que están conformando un cúmulo. Los tropos 'ordinarios' son independientes entre sí, tal como se ha supuesto tradicionalmente. El tropo de co-instanciación, sin embargo, tiene una naturaleza diferente pues, es de su esencia que no puede existir si no es conectando a los restantes tropos 'ordinarios'21. La propuesta de Maurin ha sido muy criticada por hacer esta diferencia tan marcada entre las naturalezas de los tropos 'ordinarios' y los tropos de co-instanciación. Se ha dicho, en efecto, que es una distinción ad hoc y poco simple, y que -además- tales tropos relacionales de co-instanciación parecen ser simplemente

21 Esta es la forma en que se evita un regreso al infinito vicioso. $\mathrm{Si}$, en cambio, el tropo de co-instanciación fuese un tropo como aualquier otro, entonces se requeriría algo que explicase por qué un tropo de co-instanciación está de hecho co-instanciado con los restantes tropos que conforman un ámulo. Apelar a otro tropo de co-instanciación del mismo tipo sería, nuevamente, insuficiente. Frente a este mismo problema Douglas Ehring propuso que el tropo de co-instanciación se co-instancia a sí mismo con los restantes tropos del cúmulo (cf. Ehring, 2011, 98135). 
sustratos, sólo que con otro nombre. Pero hay una diferencia crucial entre un sustrato y un tropo relacional de co-presencia. Si se postulan tropos y un sustrato, los tropos son dependientes ontológicamente del sustrato. Si se postulan tropos ordinarios y un tropo de co-instanciación $a$ la Maurin, esta relación de dependencia está invertida, pues es el tropo de co-instanciación el que es dependiente respecto de los tropos ordinarios. Esta misma inversión en la dependencia ontológica es la que ahora resulta útil. Si en vez de tener tropos monádicos hay tropos relacionales, lo que unifica un mismo nodo de la estructura resultante es un tropo relacional cuya función es precisamente efectuar tal unificación.

Cuando Maurin ha propuesto los tropos relacionales de co-instanciación, esto ha parecido una postulación ad hoc con el único propósito de evitar un regreso al infinito teóricamente incómodo. Cuando se considera la situación respecto de estructuras concretas, sin embargo, la situación varía de manera sustantiva, pues la existencia de una jerarquía generada por dependencias cuya base debe estar constituida por relaciones de primer orden independientes permite hacer inteligible cómo se pueden conformar estructuras que, en algún sentido, son esenciales y otras que son, también en algún sentido, accidentales. Una colección de relaciones de primer orden y de relaciones nodales puede conformar una 'estructura constitutiva'. No habría ningún inconveniente en suponer que algo que estamos acostumbrados a designar como un "objeto" es realmente una estructura. La esencia de este objeto es esta estructura constitutiva. Sobre esta estructura constitutiva puede venir dada una 'estructura caracterizante' que estará conformada por otras relaciones dependientes de las relaciones nodales $y$, luego, de las relaciones de primer orden que han integrado la estructura constitutiva. Estas estructuras caracterizantes pueden corresponder a lo que estamos acostumbrados a designar como un "accidente" del objeto, 
aunque se trate realmente de otra estructura dependiente de otra estructura básica. Nada impide tampoco que se generen múltiples "orbitales" de estructuras caracterizantes, cada una de ellas dependiente ontológicamente de estructuras más básicas $-\mathrm{y}$ todas ellas, últimamente, dependientes de la estructura constitutiva. Convendrá examinar estas nociones con más detención.

Un cúmulo estructural puede ser analizado como la fusión mereológica de todos y sólo los tropos relacionales de primer orden y los tropos nodales dependientes de estos, tales que los primeros están conectados por los segundos. De un modo semejante a la concepción de los 'todos pregnantes', lo que unifica a una estructura son las dependencias ontológicas entre sus partes. Se puede apreciar aquí que la distinción entre 'relación' y 'nodo' depende de la distinción entre relaciones de primer orden y relaciones de otras relaciones. Una relación de primer orden es una relación $n$-ádica independiente de otras relaciones. Una relación nodal es una relación $n$-ádica dependiente de otras relaciones, pero no toda relación de orden superior cuenta como una relación 'nodal'. En efecto, dos tropos relacionales de distancia pueden ser, por ejemplo, semejantes entre sí. La semejanza entre relaciones es una relación de relaciones, pero no cumple la función de ser un 'nodo' entre ellas. Será necesario para analizar una relación nodal introducir el concepto de argumento de una relación. Los argumentos de una relación $n$-ádica son los lugares de la totalidad de $n$-tuplas de posibles entidades conectadas por ella. Los argumentos de una relación suelen ser caracterizados como los 'espacios vacíos' que deben ser 'llenados' para que se 'complete' un hecho relacional efectivo. Aquí este 'hueco' o 'espacio' es concebido como la totalidad de entidades posibles que podrían 'completarlo'. Si se quiere, se trata del 'espacio' de todas esas entidades posibles. Por ejemplo, para una relación diádica, el espacio de sus argumentos es representable por un plano bi- 
dimensional. Cada uno de los puntos del plano representa una posible saturación de la relación por dos entidades diferentes. Cada uno de los ejes del plano es la totalidad de entidades posibles que pueden entrar en uno de los argumentos de la relación. Del mismo modo, los argumentos de una relación triádicas pueden ser representados por un espacio tridimensional. En general, los argumentos de una relación $n$-ádica pueden ser representados por un hiper-espacio $n$-dimensional. La totalidad de argumentos de una relación de primer orden son $n$-tuplas de relaciones de segundo orden, precisamente las relaciones nodales. Las relaciones nodales, entonces, pueden ser analizadas como los argumentos de las relaciones de primer orden. ¿Cuáles son ahora los argumentos de las relaciones nodales? Se trata de argumentos de relaciones de primer orden. Si se quiere, las relaciones de primer orden generan un espacio de determinación, mientras que las relaciones nodales son la determinación de ese espacio. Considérese el siguiente ejemplo:

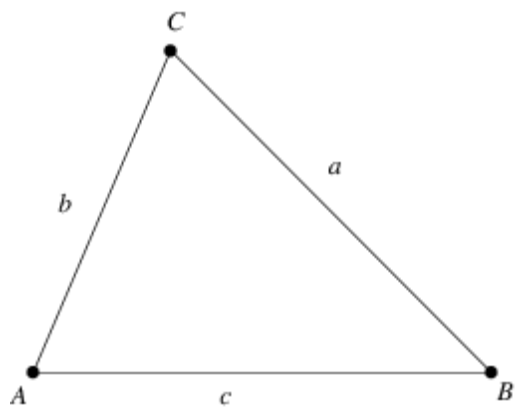

Esta estructura está constituida por tres relaciones de primer orden designadas por $a, b$ y $c$ y tres nodos designados por $A, B$ y $C$. Cada una de las relaciones de primer orden son independientes ontológicamente tanto respecto de los nodos, como respecto de las otras 
relaciones de primer orden. Se trata de relaciones 2-ádicas y se va a suponer que se trata de relaciones asimétricas. Se designarán como $A_{1}, A_{2}, \ldots$ cualquiera de los nodos que podría estar conectando a la relación $a$ en vez del nodo $A, \mathrm{y}$ de un modo semejante se designarán a $B_{1}, B_{2}, \ldots$ y a $C_{1}, C_{2}$, ... respectivamente a los nodos $B$ y $C$. La relación de primer orden $a$, por ejemplo, podría estar conectando alguna las 2-tuplas $\langle C, B\rangle,\left\langle C_{1}, B_{1}\right\rangle,\left\langle C_{2}, B_{2}\right\rangle, \ldots$ El primer argumento de $a$, entonces, es la secuencia de todos los primeros elementos de cada una de esas 2-tuplas, esto es: $C, C_{1}, C_{2}, \ldots$ El segundo argumento de $a$, es la secuencia de todos los segundos elementos de cada una de esas 2-tuplas, esto es: $B, B_{1}, B_{2}, \ldots$ El primer argumento de la relación de primer orden $a$ se designará como " $a$ ", el segundo argumento como " $a 2$ " y del mismo modo para relaciones de adicidad mayor. Los nodos o relaciones nodales, por otra parte, son ontológicamente dependientes de las relaciones de primer orden que están conectando. Así, el nodo $A$, por ejemplo, no puede sino estar conectando las relaciones $b$ y $c$, y de modo tal que sea el segundo argumento de $b$ y el primer argumento de $c$. Esto es, sus argumentos son $\left\langle b^{2}, c^{1}>\right.$. Los argumentos del nodo $B$ son, luego, $<c^{2}, a^{1}>$, y los argumentos del nodo $C$ son $<a^{2}, b^{1}>$.

Este procedimiento puede parecer ontológicamente sospechoso de un círculo en las relaciones de dependencia entre relaciones de primer orden y relaciones nodales, pero no hay tal. Las relaciones nodales dependen de relaciones de primer orden específicas. Las relaciones de primer orden, en cambio, no dependen de las relaciones nodales que, de hecho, las están conectando, pero esto no impide que puedan ser genéricamente dependientes de relaciones nodales de cierto tipo ${ }^{22}$. No es parte de la esencia de una

22 Se dice que $x$ es genéricamente dependiente de un $F$ si y sólo si la existencia de algún $F$ es parte de la esencia de $x$. De la 
relación de primer orden estar conectada por esta o esta otra relación nodal $-\mathrm{y}$, con ello, no es necesario que sea parte de esta o esta otra estructura particular- pero esto no impide que sea parte de su esencia que deba estar conectada con otras relaciones de primer orden por alguna relación nodal u otra $-\mathrm{y}$, con ello, que sea necesario que sea parte de alguna u otra estructura particular. Postular, entonces, relaciones de primer orden ontológicamente independientes de las relaciones nodales no es postular la posibilidad de relaciones de primer orden 'flotantes' como pequeñas sustancias. La asimetría ontológica entre relaciones de primer orden y las relaciones nodales, por otra parte, no obsta para que los conceptos de tales relaciones no puedan ser analizados de manera independiente. No es inteligible el concepto de 'relación de primer orden' sin la noción de 'relación nodal', así como no es inteligible el concepto de 'relación nodal' sin la noción de 'relación de primer orden'.

Una vez establecido el concepto de cúmulo estructural, pueden ser definidos los conceptos de estructura constitutiva y de estructura caracterizante. La estructura constitutiva de $x$ es el cúmulo estructural que $\chi$ es. Se trata de un cúmulo estructural -esto es, una fusión mereológica de todos y solo las relaciones de primer orden y las relaciones nodales que satisfacen la condición de que las primeras están conectadas por las segundas- que es idéntico a $x$. Resulta, entonces, que la esencia individual de $x$ está constituida por esa fusión mereológica. Recuérdese que las estructuras han sido postuladas como las entidades físicas en el nivel fundamental. También pueden estar conformando otras entidades. Lo que aquí se designa por ' $x$ ' podría ser algo

dependencia genérica de $x$ respecto de un $F$ se sigue que es necesario que, si $x$ existe, entonces existe algún $F$. Como es usual, no vale la implicación inversa. Por oposición a la dependencia genérica, la noción de dependencia precisada con anterioridad se ha denominado "dependencia rígida". 
que se nos ofrece a nuestra percepción ordinaria como un 'objeto' ocupando una región espacial continua y conectada. Podría ser un protón, o una molécula, o una 'variedad espacio-temporal'.

La estructura caracterizante de $x$, por otra parte, es la estructura (i) ontológicamente dependiente de $x$, pero (ii) numéricamente diferente de $x$. Sólo puede tener una estructura caracterizante algo que posee ya una estructura constitutiva. Si la estructura constitutiva de $x$ es su esencia individual, una estructura caracterizante es una caracterización accidental de $x$, que $x$ podría o no poseer ${ }^{23}$. Se trata de una estructura conformada, como cualquier estructura, por relaciones y nodos. Para que pueda darse una estructura caracterizante se requiere la existencia de relaciones de segundo orden. Una relación de segundo orden es una relación que conecta y depende ontológicamente de nodos saturados. Un nodo se dice saturado si y solo si está conectando las relaciones de primer orden de las que depende ontológicamente. Por lo tanto, una relación de segundo orden $r$ es una relación dependiente de nodos $n_{1}$, $n_{2}, \ldots$, tal que ninguno de $n_{1}, n_{2}, \ldots$ depende ontológicamente de $r$. La existencia de tales nodos está ya dada por la estructura que constituyen, esto es, por las relaciones de primer orden de los que dependen. Las relaciones de segundo orden pueden estar conectando sólo nodos saturados, o pueden estar siendo conectadas también por relaciones nodales de segundo orden o nodos de segundo orden. Un nodo de segundo orden depende de relaciones de segundo orden que conecta. Considérese, a modo de ejemplo, el siguiente grafo:

23 Estrictamente, no es una propiedad accidental de $x$, pues no se trata de un tropo relacional, sino de una estructura completa dependiente de la estructura constitutiva. Puede corresponder, sin embargo, a algo que intuitivamente nos aparezca como si fuese una única propiedad accidental. 


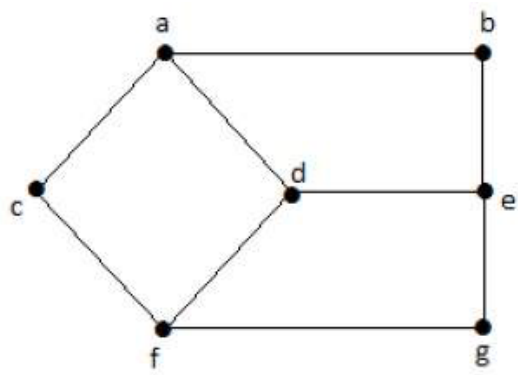

Sea que los nodos $a, c, d, f$ son los que conforman la estructura constitutiva de que se trata. Las relaciones de primer orden de tal estructura constitutiva serán designadas como $[a, d],[d, f],[f, c]$ y $[c, a]$. Estos nodos están ya 'saturados' al conformar esta estructura constitutiva, pues no se requiere nada más para garantizar su existencia. No hay en ellos, por decirlo de algún modo, ninguna deficiencia o carencia ontológica que deba ser suplementada. La estructura constitutiva, sin embargo, está siendo suplementada por una estructura caracterizante conformada por relaciones de segundo orden y nodos de segundo orden. Las relaciones de segundo orden $[a, b],[d, e],[f, g]$ dependen de los nodos $a, d$ y $f$, respectivamente. Están siendo conectadas por nodos de segundo orden $b, e \mathrm{y} g$. Estos nodos dependen de tales relaciones $[a, b],[d, e],[f, g]$. Fácilmente se puede ver que esto puede ser generalizado para $n$ niveles diferentes. En el grafo presentado, hay también relaciones $[b, e]$ y $[e, f$ entre nodos saturados de segundo orden. Estas relaciones pueden ser denominadas ahora como "relaciones de tercer orden". Nada impediría que hubiese también nodos de tercer orden, y luego relaciones de $n$-avo orden y nodos de $n$-avo orden, para un $n$ finito cualquiera.

Se podrá apreciar en este punto que es posible que vengan dadas estructuras caracterizantes sobre estructuras caracterizantes. Lo que intuitivamente puede parecer como 
un 'objeto' puede ser identificado con una estructura caracterizante junto con la estructura constitutiva de la que depende. Esta estructura ampliada puede ser la estructura constitutiva de un objeto $y$. Dada esta estructura constitutiva de $y$, nada impide que posea, a su vez, una estructura caracterizante. La nueva estructura caracterizante junto con la estructura constitutiva de la que depende puede ahora ser la estructura constitutiva de algo que intuitivamente se nos aparece como un objeto. Y este objeto puede luego poseer una estructura caracterizante. Se puede denominar como un "orbital" a la estructura caracterizante dependiente de una estructura que hace de estructura constitutiva. Esta estructura constitutiva puede incluir, a su vez, otros orbitales que son estructuras caracterizantes dependientes de sus respectivas estructuras constitutivas.

Puede resultar extraño que se identifique lo que intuitivamente parece un objeto con una estructura $o$ cúmulo estructural. Esto es lo que se hace, en efecto, cuando se postula una 'estructura constitutiva' para algo. El término "objeto", incluso en sus usos filosóficos, está muy lejos de tener un contenido preciso cuya coherencia pueda verse afectada. Es en muchos casos poco más que lo que quiera que sea que pueda entrar en el rango de una variable de primer orden. No es parte de su contenido el ser mereológicamente simple, o el tener que ocupar una región continua y conectada del espacio-tiempo, o el persistir en el tiempo siendo idéntico en distintos instantes, o ser ontológicamente independiente. Por supuesto, diferentes filósofos han querido sostener que los objetos realmente existentes satisfacen algunas o todas esas condiciones, pero se trata de añadidos controversiales. Según nuestra forma ordinaria de comprender cómo es el mundo hay una pluralidad de entidades que consideramos parte del rango de lo que hay, aun sin tener una claridad definitiva acerca de su naturaleza. Nada impide que, aunque esto sea algo 
desconocido por nosotros, tales entidades sean realmente estructuras. Lo que designamos como un 'objeto' y admitimos dentro del rango de cuantificación de primer orden será, por lo tanto, idéntico a una 'estructura constitutiva' tal como ha sido explicado. Podría suceder también que lo que consideramos intuitivamente como un objeto no pueda ser identificado con una estructura completa, sino sólo con un nodo de una estructura. La ontología de cúmulos estructurales que aquí se presenta posee suficiente flexibilidad para dejar espacio para cualquiera de tales alternativas. En las discusiones acerca del realismo estructural óntico, además, algunos han recomendado la eliminación de los 'objetos' (cf. French, 2014, 164-191), pues se trataría de una categoría ontológica confundente e inapropiada. Esto parece, sin embargo, una sobre-reacción. Es probablemente muy inadecuado pensar en el mundo como una pluralidad de pequeños cuerpos impenetrables y mereológicamente simples. En ocasiones, cuando los metafísicos hablan de "objetos" es justamente algo así lo que pareciese que tienen en mente. Sin embargo, si con la eliminación de los 'objetos' se quiere decir que no hay nada en el rango de nuestros cuantificadores de primer orden, $-\mathrm{O}$ que, por ejemplo, no hay nada que pueda satisfacer los roles de lo que usualmente entendemos por un átomo, o una molécula, o una galaxia, o una bacteriaentonces la pretendida eliminación debe ser resistida. Lo que nos ofrece la ontología de cúmulos estructurales es un repertorio mucho más sofisticado para comprender la naturaleza de esas entidades, no su eliminación.

Convendrá ahora considerar un par de alternativas a esta concepción de cúmulos estructurales.

\section{\3.2. Hechos nodales primitivos}


En muchas áreas en ontología se han propuesto diferentes 'hechos primitivos' de los que se espera que no se pida ninguna explicación. Cualquier explicación en ontología o en cualquier otro campo debe terminar en algún punto. No todo puede ser explicado. Así, por ejemplo, los nominalistas de semejanza han sostenido que las semejanzas entre objetos -lo que permite construir clases de semejanzas apropiadas para sustituir a los universalesno deben verse como relaciones tales como cualquier otra, sino como hechos 'primitivos' en los que se funda lo restante. Tal vez en este caso también se podría apelar a hechos ontológicamente primitivos acerca de nodos que conforman una estructura. De un modo análogo a los casos anteriores, el estructuralista podría en este punto pedir que tales hechos primitivos acerca de qué nodos conectan qué relaciones sean tomados sin que impliquen un compromiso ontológico con un tipo de entidad especial que merezca el nombre de "nodo". No habría incoherencia con tal procedimiento. Después de todo, cualquier teoría ontológica debe postular algunos u otros hechos primitivos.

Los hechos primitivos, sin embargo, pueden ser criticados si es que implican una falta notoria de economía -ya sea cuantitativa, por el número de entidades postuladas, o ya sea cualitativa por el número de categorías de entidades postuladas- o si es que se trata de primitivos excesivamente complejos o poco verosímiles. En muchos casos los 'hechos primitivos' parecen poco más que una explicación ad hoc. Es bien conocido -como se ha indicado arriba- lo que ha sucedido con los problemas asociados a la relación de 'instanciación' entre los universales y los objetos particulares que los ejemplifican. En una ontología de universales, una relación es una propiedad universal. La 'instanciación' debería ser un tipo de relación universal. Pero, entonces, el hecho de que tal relación de 'instanciación' esté instanciada en un universal y un objeto particular debe consistir en una relación de 'instanciación' 
entre la relación de instanciación y el par ordenado del universal y el particular. Y así al infinito. Se supone que este regreso vicioso podría ser neutralizado por la postulación de 'hechos primitivos' de instanciación. En una ontología que sólo posee como categorías fundamentales a universales y objetos particulares, los hechos de instanciación determinan qué universales están ejemplificados en qué particulares ${ }^{24} \mathrm{y}$, sin embargo, se supone que los hechos de instanciación no implican compromisos ontológicos adicionales. Esto es bien poco creible. Hay una multitud de proposiciones verdaderas acerca de la instanciación de universales en particulares, sin que parezca existir ningún 'verificador' (truthmaker) de tales verdades. Se nos pide que aceptemos como un hecho bruto que los universales están instanciados sin inquirir acerca de la naturaleza de tales 'instanciaciones'25.

Es difícil no ver una situación semejante en este caso. Para la conformación de estructuras concretas fundamentales se requieren nodos - tal es el Requerimiento nodal. Lo que se estaría sosteniendo aquí es que es un 'hecho primitivo' que las relaciones de primer orden están conectadas para conformar estructuras sin que esto deba verse como implicando que hay algo que cumple tales funciones. De este modo se evita tener que postular 'objetos' de los que las relaciones fuesen dependientes y se conseguirían las estructuras concretas buscadas. Pero esto no parece muy creible. Se pide que se acepten una multitud

\footnotetext{
24 Si los universales en cuestión son 'inmanentes', los hechos de instanciación van a fundar-además-qué universales existan.

25 Se ha hecho ver a este respecto que, si uno debe aceptar tales 'hechos primitivos' de instanciación, ¿por qué no aceptar más bien hechos primitivos correspondientes a cada uno de los supuestos universales? No parece haber necesidad de postular, por ejemplo, un universal de 'ser un $F$, pues bastaría el hecho primitivo de que algo es $F$.
} 
de proposiciones verdaderas sin un 'verificador' (truthmaker) aparente. Una concepción en estas líneas, además, tendría mucho menos flexibilidad que la postulación de relaciones nodales. Tal como se ha explicado arriba, las relaciones nodales saturadas pueden hacer de nodos para relaciones de segundo orden, y luego pueden generalizarse orbitales de dependencia con niveles de complejidad arbitrarios. Para que esto sea posible se requiere que exista algo que haga de nodo de unas y otras relaciones, pero precisamente la postulación de 'hechos nodales primitivos' pretende dispensarse del compromiso con 'algo' que cumpla las funciones de nodo ${ }^{26}$. En una concepción en estas líneas no sería inteligible algo así como una 'estructura constitutiva' o una 'estructura caracterizante'.

\section{\3.3. Dependencias simétricas}

En las ontologías de sustratos las relaciones son dependientes de los relata. Esto impide de entrada que tales relata sean dependientes de las relaciones de una estructura porque la dependencia ontológica es asimétrica. Al menos, así se ha supuesto tradicionalmente. Una salida para hacer inteligibles cúmulos estructurales con objetos que cumplan las funciones de nodos sería postular una modificación en la naturaleza de la dependencia ontológica para sostener que en estos cúmulos las dependencias entre relaciones y objetos son recíprocas. Se trataría del mismo recurso que ha sido utilizado por Husserl al postular los todos 'pregnantes'

\footnotetext{
26 Podría, por otra parte, admitirse la dependencia de los hechos nodales primitivos respecto de las relaciones de primer orden. Intuitivamente, parece razonable sostener que el hecho de que las relaciones de primer orden $r_{1}$ y $r_{2}$ estén conectadas entre sí depende ontológicamente de $r_{1}$ y $r_{2}$, aunque admitir tal cosa es también admitir un compromiso ontológico con 'hechos'.
}

Manuscrito-Rev. Int. Fil. Campinas, v. 42, n. 1, pp. 121-168, Jan-Mar. 2019. 
y que ha utilizado Peter Simons para los cúmulos nucleares. Por una parte, las relaciones son dependientes de sus relata, tal como se ha supuesto en la tradición filosófica, pero, por otra parte, los objetos -que son aquello que está siendo relacionado- dependen de las relaciones que conforman la estructura. Estos objetos son los objetos que son porque ocupan un rol específico en la estructura. Este tipo de posición es la que ha sido propuesta por varios defensores del estructuralismo óntico (cf. French y Ladyman, 2003; Ladyman, 2007, 2016a, 2016b). En esta alternativa, por una parte, se respeta la idea de que las relaciones dependen de sus relata, pero, por otra, se complementa esta idea con la suposición de que la identidad de los relata está constituida únicamente por su posición en la estructura. Los objetos poseen una esencia individual dada estructuralmente por ser exactamente los objetos relacionados con tales o cuales otros objetos. En el nivel fundamental, los objetos físicos estarían satisfaciendo el principio de identidad de los indiscernibles -al menos, los fermiones-, pues estos objetos pueden ser diferenciados entre sí por la satisfacción de diferentes relaciones simétricas entre ellos. Esto es lo que se ha denominado por algunos autores como "discernibilidad débil" (cf. Saunders, 2006). Esto es, aun cuando no existan propiedades monádicas puramente cualitativas por las que estos objetos puedan ser diferenciados entre sí, la existencia de relaciones simétricas entre ellos permite diferenciarlos como sus relata ${ }^{27}$.

27 Se dice que dos objetos $x$ e $y$ son absolutamente discernibles, si hay al menos una propiedad monádica puramente cualitativa $F$, tal que $x$ es $F$ e $y$ no es $F$, o al revés. En los fenómenos de entrelazamiento cuántico precisamente sucede que no hay propiedades intrínsecas que puedan ser atribuidas determinadamente a las partículas en tal estado. Se dice que $x$ e $y$ son relativamente discernibles si y solo si hay al menos una relación asimétrica puramente cualitativa $R$, tal que $R x y$. Se dice que $x$ e $y$ son débilmente discernibles si y solo si hay al menos una relación 
Esta alternativa puede parecer de entrada mucho menos revisionaria que la postulación de relaciones nodales, pues no se está dispensando de objetos, sino simplemente modificando la dependencia ontológica de esos objetos y las estructuras que integran. Sucede, sin embargo, que esta reforma de la dependencia ontológica es un precio alto que pagar. No es este el lugar para hacer una discusión detallada de las cuestiones involucradas en una dependencia ontológica simétrica. Lo que puede mostrarse aquí es que se trata de una reforma, por lo menos, muy sospechosa y que debe ser tratada con extrema cautela. Hay muy buenos motivos para mantener la suposición tradicional de que la dependencia es un orden estricto, esto es, una relación irreflexiva, asimétrica y transitiva. En primer lugar, la dependencia ontológica es claramente transitiva. En efecto, si $x$ depende ontológicamente de $y$ es porque la existencia de $y$ es parte de la esencia de $x$, de tal modo que sin la existencia de $y, x$ no existiría. Supóngase que $y$, a su vez, depende ontológicamente de $z$, esto es, la existencia de z es parte de la esencia de $y$ de manera que, sin la existencia de $\%$ y no existiría. ¿Cómo podría ahora $x$ no depender ontológicamente de ? Si se requiere la existencia de ₹para la existencia de $y$, y se requiere la existencia de $y$ para la existencia de $x$, parece obvio que se requiere la existencia de z. para la existencia de $x$. En segundo lugar, la dependencia ontológica es una relación irreflexiva. Se trata, en efecto, de una relación de prioridad ontológica, pero nada puede ser

simétrica puramente cualitativa $S$, tal que $S x y$. Una propiedad se dice puramente cualitativa si es que no induye ningún objeto particular. Una propiedad no puramente cualitativa, por el contrario, es una propiedad que induye a un objeto particular, tal como 'estar a diez metros de Sócrates' o 'ser idéntico a Sócrates'. 
prioritario respecto de sí mismo. Pero una relación que sea irreflexiva y transitiva debe ser también asimétrica ${ }^{28}$.

Otra debilidad de esta alternativa en comparación con la postulación de relaciones nodales es que no se podría hacer inteligible la distinción entre estructuras caracterizantes y estructuras constitutivas. Dado que las relaciones de dependencia ontológica son, por hipótesis, simétricas, no habría manera de hacer el contraste entre una estructura que fuese esencial para algo y otra que no lo fuese. Cuando se trata de un plexo de relaciones que conforman una estructura, todos los constituyentes de esa estructura son por igual esenciales para ella. La flexibilidad de los cúmulos estructurales con relaciones nodales no puede ser replicada mediante dependencias simétricas.

\section{$\int 4$. CONCLUSIONES}

Se ha presentado aquí cómo es que puede hacerse inteligible una estructura física fundamental del tipo de aquellas que han sido propuestas en los últimos veinte años en distintas discusiones en filosofía de la física. Muchos críticos de estas propuestas, en efecto, han sostenido que la mera idea de una 'estructura física fundamental' sería incoherente porque una estructura, esto es, un plexo de relaciones, exige objetos que estén siendo relacionados. De este modo, la suposición de que en el nivel fundamental lo que hay son estructuras, requeriría suponer que hay objetos ontológicamente prioritarios respecto de la estructura, por lo que las estructuras en cuestión no son fundamentales.

${ }^{28}$ En efecto, supóngase por hipótesis que hubiese una relación $R$ irreflexiva y transitiva. Si $R x y$ y $R y x$ se seguiría por transitividad que $R x x$, lo que está en contradicción de la irreflexividad supuesta. 
$\mathrm{Al}$ examinar las principales familias de teorías acerca de la naturaleza de un particular -las ontologías de sustratos y las ontologías de cúmulos- se aprecia efectivamente que, o bien resultaría que las estructuras deberían ser dependientes de sustratos, o bien no podría haber estructuras en lo absoluto. Un examen más detenido de la cuestión, sin embargo, muestra que las críticas a la inteligibilidad de las estructuras físicas fundamentales han tenido a la vista un rango de ontologías demasiado restringido. Hay varios modos de hacer inteligible lo que se denomina aquí un "cúmulo estructural": postulando nodos primitivos, postulando dependencias ontológicas simétricas, o postulando tropos relacionales nodales. Hay varias ventajas teóricas importantes que la tercera alternativa posee y que la hacen preferible a las restantes alternativas. En cualquier caso, no hay ningún problema de coherencia con la suposición de estructuras físicas fundamentales tal como las han propuesto los defensores de diferentes formas de estructuralismo óntico. Por supuesto, esto está lejos de ser una justificación en toda regla de tales propuestas. Tal cosa deberá hacerse mediante un examen mucho más delicado que deberá proseguirse. Lo que se ha mostrado aquí, sin embargo, es que la adjudicación de tales propuestas no puede resolverse por la vía rápida de condenarlas por incoherencia ${ }^{29}$.

29 Este trabajo se ha redactado en ejecución del proyecto de investigación Fondecyt 1160001 (Conicyt, Chile). Muchas de las ideas que aquí se exponen han sido presentadas en diversos auditorios en las Jornadas Rolando Chuaqui, la Pontificia Universidad Católica de Chile, la Universidad Alberto Hurtado y la Universidad de Buenos Aires. Agradezco los comentarios y sugerencias recibidas en esas ocasiones. Agradezco también las observaciones de Cristián Soto a una versión preliminar, y las observaciones de un evaluador anónimo de esta revista. 


\section{REFERENCIAS}

Albert, D. Z. Quantum Mechanics and Experience, Cambridge, Mass.: Harvard University Press, 1992.

ARISTÓTELES, Categorías. Sobre la interpretación. Introducción, traducción y notas de Jorge Mittelmann. Buenos Aires: Losada, 2009.

Armstrong, D. M. Universals and Scientific Realism, Volume 1, Nominalism and Realism, Cambridge: Cambridge University Press, 1978a.

Universals and Scientific Realism, Volume 2, A Theory of Universals, Cambridge: Cambridge University Press, 1978b.

A World of States of Affairs, Cambridge: Cambridge University Press, 1997.

Balakrishnan, R. y Ranganathan, K. A Textbook of Graph Theory, New York: Springer, 2012.

Bokulich, P. y Bokulich, A. (eds.) (2011), Scientific Structuralism, New York: Springer.

BRICEÑO, S. y MUMFORD, S. "Relations All the Way Down? Against Ontic Structural Realism" en Marmodoro y Yates (2016), 198-217.

BROWER, J. "Aristotelian vs Contemporary Perspectives on Relations” en Marmodoro y Yates (2016), 36-54.

CaO, T. Y. "Can We Dissolve Physical Entities into Mathematical Structure?”, Synthese 136, 57-71, 2003.

CAMPBELl K. "The Metaphysic of Abstract Particulars" Midwest Studies in Pbilosophy 6, 477-488, 1981. Abstract Particulars, Oxford: Blackwell, 1990. 
ChAKRAVARTTY A. "The Structuralist Conception of Objects”, Philosophy of Science 70, 867-878, 2003.

Correia, F. y SCHNIEDER, B. (2012), "Grounding: An Opinionated Introduction" en Fabrice Correia y Benjamin Schnieder (eds.), Metaphysical Grounding. Understanding the Structure of Reality, Cambridge: Cambridge University Press, 1-36.

Cowling, S. Abstract Entities, London: Routledge, 2017.

Denkel, A. Object and Property, Cambridge: Cambridge University Press, 1996.

Ehring, D. Tropes. Properties, Objects, and Mental Causation, Oxford: Oxford University Press, 2011.

ESFELD, M. "Quantum Entanglement and a Metaphysics of Relations", Studies in History and Pbilosophy of Modern Physics 35, 601-617, 2004.

____ y Lam, V. "Ontic Structural Realism as a Metaphysics of Objects" en Bokulich y Bokulich (2011), 143-160.

FINE, K. "Ontological Dependence", Proceedings of the Aristotelian Society 95, 269-290, 1995.

FRENCH, S. The Structure of the World. Metaphysics and Representation, Oxford: Oxford University Press, 2014.

_____ y Krause, D. Identity in Physics: A Historical, Philosophical, and Formal Analysis, Oxford: Clarendon Press, 2006.

y Ladyman, J. "Remodelling Structural Realism: Quantum Physics and the Metaphysics of Structure", Synthese $136 \mathrm{~N}^{\circ}$ 1, 31-56, 2003.

$\mathrm{y}$ "In Defense of Ontic Structural Realism" en Bokulich y Bokulich (2011), 25-42. 
Alexandre GuAY y ThOmas Pradeu (eds.) (2016), Individuals Across the Sciences, Oxford: Oxford University Press.

HeIL, J. From an Ontological Point of View, Oxford: Clarendon Press, 2003.

The Universe as We Find It, Oxford: Clarendon Press, 2012.

Hoffman, J. y Rosenkrantz, G. S. Substance Among Other Categories, Cambridge: Cambridge University Press, 1994.

Husserl ,E. (1900/1901), Investigaciones lógicas, Barcelona: Altaya, 1929. Traducción de la segunda edición alemana de Manuel García Morente y José Gaos.

LADYMAN, J. "What is Structural Realism?", Studies in History and Philosophy of Science 29, 409-424, 1998.

"On the Identity and Diversity of Objects in a Structure", Proceedings of the Aristotelian Society. Supplementary Volume 81, 23-43, 2007.

(2014), "Structural Realism" en Ed Zalta (ed.), Stanford Encyclopedia of Philosophy, https:/ / plato.stanford.edu/ entries/structuralrealism/.

"The Foundations of Structuralism and the Metaphysics of Relations" en Marmodoro y Yates, 177-197, 2016 .

"Are There Individuals in Physics, and If So, What Are They?” en Guay y Pradeu, 193-206, 2016b.

, Ross, D., Spurrett, D. y Collier, J. Every Thing Must Go. Metaphysics Naturalized, Oxford: Oxford University Press, 2007. 
LAM, V. "Structuralism in the Philosophy of Physics", Philosophy Compass, doi10.1111/phc3.12421, 2017.

LEWIS, D. On the Plurality of Worlds, Oxford: Blackwell, 1986.

Lowe, E. J. The Four-Category Ontology. A Metaphysical Foundation for Natural Science, Oxford: Clarendon Press, 2006.

Marmodoro, A. y Yeats, D. (eds.) (2016), The Metaphysics of Relations, Oxford: Oxford University Press.

Martin, C. B. "Substance Substantiated" Australasian Journal of Philosophy 58, 3-10, 1980.

MAURIN, ANNA-SofIA If Tropes, Dordrecht: Kluwer, 2002.

McKenzIE, K. "Priority and Particle Physics: Ontic Structural Realism as a Fundamentality Thesis", The British Journal for the Philosophy of Science 65, 353-380, 2014.

Mertz, D. W. Moderate Realism and its Logic, New Haven: Yale University Press, 1996.

Morganti, M. "On the Preferability of Epistemic Structural Realism”, Synthese 142, 81-107, 2004.

O'Leary-Hawthorne, P. y COVER, J. A. "A World of Universals” Philosophical Studies 91, 205-219, 1998.

PARSONS, C. (1990), "The Structuralist View of Mathematical Objects", Synthese $84 \mathrm{~N}^{\circ} 3$, 303-346. Reimpreso en W. D. Hart (ed.), The Philosophy of Mathematics, Oxford: Oxford University Press, 1996, 272-309. Se utiliza esta última versión. 
Psillos, S. "The Structure, the Whole Structure, and Nothing But the Structure?", Pbilosophy of Science 73, 560-570, 2006.

Rickles, D., French, S. y Saatsi, J. (eds.) (2006), The Structural Foundations of Quantum Gravity, Oxford: Clarendon Press.

ROJAS, I. Ontología cuántica: de los objetos a las estructuras. Tesis de Magister presentad a en la Universidad de Santiago de Chile, 2017.

SAUnders, S. "Are Quantum Particles Objects?", Analysis $66 \mathrm{~N}^{\circ} 1,52-63,2006$.

Simons, P. (1982), “The Formalisation of Husserl's Theory of Wholes and Parts" en Barry Smith (ed.), Parts and Moments. Studies in Logic and Formal Ontology, München-Wien: Philosophia Verlag, 113-159.

"Particulars in Particular Clothing: Three Trope Theories of Substance" Philosopby and Phenomenological Research 54, 553-576, 1994.

WiLliams, D. C. "On the Elements of Being I" Review of Metaphysics 7, 3-18, 1953 a.

______ "On the Elements of Being II" Review of Metaphysics 7, 171-192, 1953b.

Williamson, T. Modal Logic as Metaphysics, Oxford: Oxford University Press, 2013.

Worrall, J. “The Best of Both Worlds?”, Dialectica 43, 99124, 1989.

\section{(cc) $\mathrm{EY}$}

